\title{
Per Nanoliter
}

National Cancer Institute

\section{Source}

National Cancer Institute. Per Nanoliter. NCI Thesaurus. Code C116243.

A volume unit equal to one nanoliter used as a denominator to build a derived unit expressed as a ratio. 